\title{
Lona Cultural Itinerante: Uma Proposta De Intervenção Política E Cultural
}

\section{Itinerant Cultural Canvas: A Proposal for Political and Cultural Intervention}

\author{
DOI: $10.46814 /$ lajdv2n6-023
}

Recebimento dos originais: 01/09/2020

Aceitação para publicação: 30/10/2020

\author{
Marcia Barros Ferreira Rodrigues \\ Pós doutora pela UFF em Ciência Política, Doutora em História Social pela USP. Professora Titular \\ da Universidade Federal do Espírito Santo (UFES) \\ E-mail: mbfrodrigues@gmail.com
}

\section{Clarkson Machado Diniz}

Doutor em História Social das Relações Políticas pelo PPGHIS/UFES, mestre em Administração pela UFES. Professor do IFES no curso de Administração, campus Cariacica

E-mail: clarksondiniz@gmail.com

\section{Rosely da Silva Pires}

doutoranda no PPGSD da UFF, mestrado em Educação, área de concentração em políticas públicas pela Universidade Federal Fluminense. Professora Assistente da UFES

E-mail: roselysilvapires@ @otmail.com

\section{RESUMO}

O presente artigo se inscreve no âmbito temático das políticas culturais e tem como objeto de reflexão o homicídio juvenil. O estado do Espírito Santo é tomado como escopo empírico, particularmente os municípios de Serra e Vitória. O objetivo geral é propor um projeto de intervenção e prevenção ao envolvimento dos jovens no crime do homicídio onde o Brasil e o ES ocupam lugar de destaque nas estatísticas criminais mundiais. O público alvo são jovens entre $12 \mathrm{e}$ 18 anos em situação de vulnerabilidade social. A metodologia toma como ferramenta base atividades artístico-culturais, articuladas a quatro princípios: o protagonismo, enquanto respeito ao desejo do sujeito; a responsabilização como processo de conscientização das consequências dos atos praticados, a sociabilidade positiva como aprendizado coletivo e solidário no uso do espaço comum e o principio fundamental do exercício consciente da cidadania.

Palavras-chaves: Política cultural, arte, juventude, crime e cidadania.

\section{ABSTRACT}

This article is part of the thematic scope of cultural policies and its object of reflection is juvenile homicide. The state of Espírito Santo is taken as an empirical scope, particularly the municipalities of Serra and Vitória. The general objective is to propose an intervention and prevention project for the involvement of young people in the crime of homicide, where Brazil and the ES occupy a prominent place in world criminal statistics. The target audience is young people between 12 and 18 years old in a situation of social vulnerability. The methodology takes artistic-cultural activities as a basic tool, articulated to four principles: protagonism, while respecting the subject's desire; accountability as a process of raising awareness of the consequences of the acts performed, positive sociability as a collective and solidary learning in the use of common space and the fundamental principle of conscious exercise of citizenship. 
Keywords: Cultural policy, art, youth, crime and citizenship.

\section{INTRODUÇÃO}

O presente artigo se inscreve no âmbito temático das políticas culturais e tem como objeto de reflexão uma proposta de intervenção na vitimização do crime do homicídio no Brasil. Especificamente nossa proposta toma como escopo empírico o homicídio no Espírito Santo em particular nos municípios de Serra e Vitória na Região metropolitana da Grande Vitória. Nosso objetivo é realizar uma reflexão e propor uma intervenção em caráter preventivo ao envolvimento dos jovens no crime de homicídio. O público alvo são jovens entre 12 e 18 anos em situação de vulnerabilidade social. A metodologia proposta é fruto das experiências e conhecimentos acumulados e obtidos por nossa equipe permanente há mais de uma década. ${ }^{1} \mathrm{O}$ diferencial metodológico da proposta Lona Cultural Itinerante é a ênfase nas atividades artístico-culturais como ferramentas articuladas a quatro princípios: o protagonismo, a responsabilização, a sociabilidade positiva enquanto aprendizado coletivo e solidário no uso do espaço comum e o por último, o principio fundamental do exercício consciente da cidadania.

Nossa proposta tem uma perspectiva geral e um olhar particular. Ou seja, ajustada as especificidades culturais locais, propomos uma metodologia denominada Formação em Cidadania Cultural (FCC), que apresenta um novo paradigma para projetos de intervenção social preventiva com jovens em situação de vulnerabilidade social em nível nacional e local. Nossa perspectiva, sustentada em nossa experiência, parte do princípio de que é possível formar jovens cidadãos a partir da cultura por meio da arte. Desde que a sustentabilidade das potencialidades desenvolvidas pelo exercício efetivo do protagonismo juvenil seja garantida para que seja possível o exercício da cidadania consciente. Isso implica necessariamente na negação explícita do autoritarismo, que decide os projetos de cima para baixo sem escutar e respeitar as demandas do sujeito, do paternalismo e do assistencialismo que perpetuam as vulnerabilidades e não contribuem para o exercício da cidadania.

\footnotetext{
${ }^{1}$ Diagnóstico sócio criminal, Serra Cidade da Paz em, 2006-2007; diagnóstico Serra: Agenda do Futuro 2012-2032 realizado em 2012; consultoria realizada em 2011 na ONU HBITAT em São Pedro, por meio do projeto "Segurança Cidadã: prevenindo a violência e fortalecendo a cidadania com foco em crianças, adolescentes e jovens em condições vulneráveis em comunidades brasileiras"; visita técnica, realizada em maio de 2014 ao México, com financiamento da FAPES, à ONG Circo Volador, premiada pela ONU e que atua desde 2004 em contexto social com jovens, muito similar ao canário capixaba. Projetos de extensão pela UFES realizados em São Pedro em parceria com a LBV no bairro de Inhanguetá. Esses projetos de extensão da UFES atuam com jovens voltados a prevenção à violência
} 


\section{JUSTIFICATIVA E FONTES}

O homicídio de jovens no Brasil é um fenômeno que vem chamando a atenção há um longo tempo por parte tanto dos órgãos internacionais (ONU e UNESCO) quanto do campo acadêmico, com produções maciças e comprobatórias da tese de que está em curso: o genocídio juvenil (Mapa da Violência: 2014). Entretanto, a despeito de todos os diagnósticos e prognósticos produzidos ao longo das últimas décadas esse quadro não apresenta sinais de arrefecimento, o que faz com que cada vez mais a sociedade e seus diversos segmentos sejam conclamados a agir, conforme as possibilidades das organizações públicas e privadas no âmbito econômico, social, político, cultural e educacional. Nesse sentido, a despeito da nossa Constituição Federal e o Estatuto da Criança e o do Adolescente (1990), quanto os Documentos internacionais como a Declaração Universal dos Direitos Humanos (1948), Declaração sobre o Direito ao Desenvolvimento (1986) e a Declaração Universal dos Direitos da Criança e Adolescente (1959), estabelecerem determinações claras acerca da responsabilidade de todos quanto à garantia não só da vida, mas também ao bem-estar e direito ao desenvolvimento dos jovens, torna-se crucial a participação do estado e da sociedade civil na promoção desses direitos. Diante desse quadro, a prerrogativa fundamental dessa proposta se assenta no fortalecimento da educação para a paz e a necessidade de uma aproximação mais efetiva e afetiva dos jovens e adolescentes em busca de um processo de sensibilização e conscientização desse sujeito de direito quanto à sua real importância na sociedade e no futuro do país e no exercício pleno da cidadania.

Segundo a Organização Mundial da Saúde (2014), o Brasil tem o maior número absoluto de homicídios no mundo. De cada 100 assassinatos no mundo, 13 são no Brasil. Segundo o documento, o total de homicídios no mundo chegou a 475 mil. Os dados são de 2012. O Brasil é o líder no ranking. O governo brasileiro informou 47 mil homicídios em 2012, mas a OMS estima que o número real tenha sido muito superior: mais de 64 mil homicídios. Depois do Brasil aparecem Índia, México, Colômbia, Rússia, África do Sul, Venezuela e Estados Unidos. Se for levado em consideração o número de crimes e o tamanho da população, ou seja, em termos proporcionais, Honduras é o primeiro país da lista, seguido pela Venezuela. O Brasil, nesse cálculo, surge como o $11^{\circ}$ lugar. A OMS calcula que no Brasil a cada 100 mil pessoas, 32 sejam assassinadas, a faixa etária de concentração dessas mortes é entre 15 e 25 anos. O víeis racial também chama atenção

Já o estado do Espírito Santo, nas três últimas décadas entre 1979-2009 apresentou um crescimento real de cerca de 700\% no número de homicídios, saltando de 256 (12,65 homicídios por 100mil habitantes) no final da década de 1970, para 2034 homicídios em 2009 (58,32 homicídios por 100mil habitantes). Segundo dados oficiais da Secretaria Especial de Ações Estratégicas do ES, de 2010 a 2014, houve um pequeno decréscimo nos números, mais continua muito acima do 
considerado tolerável. A Região Metropolitana da Grande Vitória é responsável por cerca de $70 \%$ do total de homicídios no Espírito Santo. Entretanto, esse tipo de crime não ocorre de forma uniforme no ambiente metropolitano, mas restrito a alguns bairros, ou conjunto de bairros, via de regra, de forma concentrada e em regiões com elevada densidade demográfica, de ocupação recente (nos últimos 30 anos), com baixo índice de urbanização, infraestrutura habitacional e desenvolvimento socioeconômico. A escolha dos municípios de Serra e Vitória se justifica pelo fato desses municípios integrarem a RMGV que concentra cerca de $70 \%$ dos crimes de homicídios do estado. Segundo dados primários do CIODES (Centro Integrado Operacional de Defesa Social da PM/ES) e consolidados pela SEAE/ES - Secretaria Especial de Ações Estratégicas, na série temporal de 20052013, considerando os homicídios dolosos consumados, incluindo tentativa de homicídio com comunicado de morte, o estado do Espírito Santo apresenta os seguintes números absolutos.

ÍNDICES DE SERRA NOS BAIRROS DE FEU ROSA E VILA NOVA DE COLARES E INHANGUETÁ EM SÃO PEDRO

\begin{tabular}{|l|l|l|l|l|l|l|l|l|l|l|}
\hline & $\mathbf{2 0 0 5}$ & $\mathbf{2 0 0 6}$ & $\mathbf{2 0 0 7}$ & $\mathbf{2 0 0 8}$ & $\mathbf{2 0 0 9}$ & $\mathbf{2 0 1 0}$ & $\mathbf{2 0 1 1}$ & $\mathbf{2 0 1 2}$ & $\mathbf{2 0 1 3}$ & $\mathbf{2 0 1 4}$ \\
\hline ESPIRITO SANTO & 1.704 & 1.857 & 1.903 & 1958 & 2.034 & 1.845 & 1.709 & 1.702 & 1.565 & \\
\hline RMGV & 1.202 & 1.288 & 1.330 & 1.358 & 1.315 & 1.175 & 1.098 & 1.044 & 964 & \\
\hline SERRA & - & - & - & - & - & - & - & 344 & 344 & 155 \\
\hline CARIACICA & - & - & - & - & - & - & - & 289 & 222 & 113 \\
\hline VILA VELHA & - & - & - & - & - & - & - & 216 & 204 & 117 \\
\hline VITÓRIA & & & & - & - & - & - & 113 & 116 & 55 \\
& - & - & - & - & - & - & - & & \\
\hline
\end{tabular}

Fonte: Centro Integrado Operacional de Defesa Social da PM/ES) e SEAE/ES - Secretaria Especial de Ações Estratégicas, série temporal de 2005-2013.

\begin{tabular}{|c|c|c|c|c|c|}
\hline \multicolumn{7}{|c|}{ HOMICÍDIOS 2014 } \\
\hline MESES & VITORIA & SERRA & CARIACICA & VILAVELHA & TOT MÊS \\
\hline JAN & 12 & 40 & 25 & 25 & 102 \\
\hline FEV & 14 & 28 & 26 & 21 & 89 \\
\hline MAR & 11 & 34 & 24 & 22 & 91 \\
\hline ABR & 9 & 24 & 17 & 24 & 74 \\
\hline MAI & 9 & 29 & 21 & 25 & 84 \\
\hline TOT CIDADE & 55 & 155 & 113 & 117 & \\
\hline
\end{tabular}

Fonte: Centro Integrado Operacional de Defesa Social da PM/ES) e SEAE/ES - Secretaria Especial de Ações Estratégicas, série temporal de 2005-2013

Diante do exposto, a escolha do escopo empírico para nossa reflexão e proposta selecionou no Espírito Santo os bairros de Feu Rosa e Vila Nova de Colares no município de Serra, em função dos 
altos índices de homicídio juvenil, por serem bairros limítrofes e por termos identificado em pesquisa anterior, uma divisão simbólica entre os moradores que se dividem entre estabelecidos e outsides (Rodrigues: 2009). Dessa forma, nossa proposta prevê a instalação da Lona Cultural Itinerante, estrategicamente num ponto de intersecção entre esses dois bairros com a intenção de provocar uma reflexão sobre essa divisão e a possibilidade de integração de convívio. Essa estratégia é em função de não se observar em Feu Rosa e Vila Nova de Colares um acirramento entre gangues pela disputa do tráfico.

Já no município de Vitória a escolha foi o bairro de Inhanguetá na grande São Pedro, em função da estimada redução dos índices de homicídio em São Pedro, pela Secretaria Estadual de Ações Eestratégicas/ES, em contraposição a nossa observação e experiência. A escolha de um só bairro no município de Vitória é em função da complexidade da dinâmica criminal da grande São Pedro, onde foi identificado grande disputa de gangues pelo tráfico no local. Sendo assim, o bairro de Inhanguetá ao mesmo tempo exige uma ação preventiva e concomitantemente tem uma dinâmica criminal ameaçadora e baseada no medo, que dificulta a circulação dos jovens no bairro. Entretanto, a parceria da LBV é importante pois além de atuar há 49 anos no local é um espaço neutro e estratégico e que detém um cadastro dos jovens até 12 anos o que permite acesso privilegiado à nossa população alvo (12 a 18 anos), pois a despeito de está fora da atuação da LBV, pela faixa etária e também pela metodologia e abordagem, o cadastro nos permite localizar o público alvo. Quanto ao local de instalação da Lona Cultural Itinerante, nesse bairro, deve garantir a circulação dos jovens sem conflito com as gangues. Para o êxito do projeto a duração da intervenção da Lona Cultural Itinerante nesses locais é estimada em no mínimo 2 anos, respectivamente.

\subsection{LOGÍSTICA DO PROJETO}

Nossa proposta prevê realizar uma etapa prévia de mobilização, a partir da aprovação, com o poder público local - Prefeituras, buscando apoio legal e logístico para a instalação da Lona no local indicado, garantindo segurança e preservação em termos de defesa social. A etapa prévia consiste em informar e buscar apoio logístico do gestor público - isso é o Prefeito dos municípios de atuação da Lona Cultural Itinerante. O instrumento para isso é o plano de comunicação realizado pelo coordenador geral do projeto e produtor cultural. O espaço físico de realização do projeto Lona é uma lona com capacidade para 500 pessoas, formato circo ou aranha, com 500 metros quadrados. Infraestrutura inclusa: montagem, banheiro químico e cerca. O espaço físico da Lona se justifica pelo fato de proporcionar um espaço autônomo e neutro, com dimensões para abrigar todas as atividades previstas no projeto e que acontecerão simultaneamente possibilitando a circulação dos jovens em 
diversas atividades facilitando o convívio comum, a responsabilidade pela limpeza e organização do espaço, buscando a sociabilidade solidária, fundamental para o exercício da cidadania e execução da nossa proposta metodológica. Quanto à estrutura logística de instalação e funcionamento da Lona está previsto no escopo do projeto. Entretanto é necessário parceria antes do início do projeto, com o poder público local - Prefeituras, no sentido de otimizar a preservação e o funcionamento da Lona durante o período execução.

Os critérios de seleção da população alvo deverá ter a duração de um mês em cada município e pelo caráter preventivo do projeto a seleção dos beneficiários diretos terá critérios específicos: Jovens que tenham o perfil de vítimas do crime do homicídio: majoritariamente do gênero masculino; classes C, D, E; afrodescendentes; moradores dos bairros selecionados; faixa etária de 12 a 18 anos; fora da escola ou envolvido em conflitos ou atos indisciplinares; fora do mercado formal; situação de vulnerabilidade social dada pela sujeição criminal: características genotípicas, fenotípicas e culturais. Por quê? Pelo fato da sujeição criminal legitimar uma identificação prévia que criminaliza o sujeito. Por sujeição criminal entendemos o processo de criminalização que reforça estereótipos, aciona ódios recíprocos e tece uma teia de significados que possibilitam a suspeição. Ou seja, características genotípicas, fenotípicas e culturais que estigmatizam o sujeito tornando-o suspeito previamente da ação criminal, tais como: cor, tipo físico, vestuário, gosto musical, local de moradia e linguagem. Nesse sentido, nossos critérios de seleção pretende atingir diretamente esse público para fortalecer os laços de proteção e solidariedade no local de vivência desses jovens, oferecendo possibilidades de formação cultural por meio da arte, protagonismo e exercício da cidadania, agindo pontualmente na prevenção a vulnerabilidade que sustenta a sujeição criminal. (Rodrigues, M.B.F e Dadalto, M.C:2014).

Os instrumentos de seleção serão diferenciados por bairros de acordo com o conhecimento prévio da realidade local em relação ao público alvo por meio de diagnósticos existentes ou a ser realizado. Incluí-se também contato com lideranças informais, grupos de enfoque com a população alvo e entrevistas com a população alvo, cadastro socioeconômico, relatórios das atividades de projetos de extensão e grupos de enfoque com a população alvo. A Meta da seleção é identificar jovens em situação de vulnerabilidade social dada pela sujeição criminal para selecionar os beneficiários.

\section{METODOLOGIA}

Nossa metodologia é fruto das experiências e conhecimentos acumulados e obtidos por nossa equipe permanente em vários projetos tanto de pesquisa quanto de intervenção realizados nos 
municípios do estado do Espírito Santo em particular, Serra e na grande São Pedro, o que atesta nossa expertise, capacidade técnica e acadêmica para atuação na área temática proposta. Contendo uma proposta local que pode ser generalizada para uma ampliação regional ou nacional.

A partir do panorama apresentado pelos dados empíricos que comprovam a gravidade da situação do homicídio juvenil no Brasil e especificamente, no Espírito Santo. Enfatizamos que o projeto Lona Cultural itinerante busca atuar na prevenção do envolvimento dos jovens no crime e contribuir na diminuição dos altos índices de homicídio que vitimiza os jovens nas Regiões metropolitanas em geral. O diferencial metodológico do projeto Lona Cultural itinerante é a ênfase nas atividades artístico-culturais, como ferramenta, articuladas de forma dialética a quatro princípios: O protagonismo, entendido como respeito ao desejo do sujeito; a responsabilização enquanto processo de conscientização das consequências dos atos praticados, a sociabilidade positiva enquanto aprendizado coletivo e solidário no uso do espaço comum; o principio fundamental do exercício consciente da cidadania.

Em função dos princípios enunciados, nossa intervenção parte da Oficina Base da Formação em cidadania cultural (FCC), denominada "Essência e Existência do SER", como início do tratamento do problema. O funcionamento da Lona tem a seguinte logística: A Lona comportará todas as atividades do Projeto desde a primeira etapa: Oficina Base com suas atividades até a segunda etapa com as quatro oficinas, que funcionarão simultaneamente. Portanto, perfazendo um período de 10 meses, nos bairros selecionados, respectivamente. A terceira etapa (2 meses) é avaliação, monitoramento e relatório. Para tal a Lona precisa ter uma dimensão espacial suficiente para abrigar as atividades da Oficina de base com funcionalidade e os três palcos, onde acontecerão as oficinas de teatro, música e dança e um espaço para livre para a oficina de desenho.

A ideia da Lona Cultural Itinerante é a de movimento num mesmo espaço físico. Um espaço de trânsito e convívio comum em diversas atividades simultâneas. A Lona Cultural Itinerante concentra suas ações em atividades artístico-culturais por entender que a arte é o meio eficaz para atingir o jovem no seu desejo. E por isso, instrumento fundamental no estabelecimento do diálogo. Exatamente por ser o meio por excelência da manifestação da expressão humana. O funcionamento da Lona enquanto espaço de trânsito é primordial para o estabelecimento de limite e obedece a orientação pedagógica que estimula a convivência solidária e criativa com respeito ao espaço comum como exercício fundamental da cidadania.

A primeira Etapa do Projeto deverá ter a duração de 2 meses, sendo 3 vezes por semana. A Oficina Base do FCC é a primeira fase do projeto e constituí um diagnóstico prévio e pontual que visa o delineamento da essência do sujeito, no caso jovens em situação de vulnerabilidade social, por 
meio da valorização da sua fala, da escuta e percepção sensorial de suas demandas, como meio de capturar e identificar as subjetividades, as identidades, o sentimento de pertencimento social, a identificação das vulnerabilidades aos quais estes jovens estão sujeitados (sujeição criminal), o despertar das potencialidades e o exercício da cidadania por meio da arte. Entendida por nós, como única forma de integralizar o indivíduo esfacelado e torná-lo cidadão (Berlinck: 1998).

O enfoque metodológico das atividades da Oficina Base em FCC "Essência e Existência do SER”, deverá operar em dois níveis: Situações experienciais: Nesse $1^{\circ}$ nível opera-se com atividades simples que permitam aos jovens o compartilhamento de experiências individuais e coletivas e que viabilizem a escuta e a percepção sensorial de suas demandas. Para tal, serão criados processos que favoreçam o clima de espontaneidade das diversas formas de expressão. Atividades: Jogos, dramatizações, relatos de casos, vídeos, desenhos, exercícios de musicalidade e dança. A coleta de dados se dará por: Relatórios das demandas produzidos pela observação participante dos profissionais envolvidos nas atividades. Profissionais: Artista plástico, psicólogo e musicista com experiência no trato com o público alvo. A meta parcial do nível 1 é: Destacar e valorizar os elementos motivadores da expressão da subjetividade da população alvo como forma de incentivar o exercício da cidadania. Rodas de discussão.

No $2^{\circ}$ nível opera-se com a análise dos relatórios gerados destacando as sensações, emoções e demais efeitos percebidos na primeira fase. Neste nível trata-se não apenas de experimentar situações novas, expor com liberdade sentimentos e ideias, mas principalmente da reflexão sobre a importância do exercício da cidadania enquanto direito de expressão do indivíduo. Atividade: Debate dirigido ou livre, conforme o caso, com intervenção dos participantes e dos observadores. Profissionais: Sociólogo e psicólogo especializados no tema e com experiência no trato com o público alvo. Coleta de dados - Os dados serão coletados pelos observadores que dirigiram os debates e que farão os relatórios. Meta parcial do nível 2: Registro e confecção coletiva de um mapa da cultura local, das subjetividades, do pertencimento social, das vulnerabilidades expressas pelas características da sujeição criminal e potencialidades da população alvo. Número de beneficiários na primeira etapa será de 200 jovens nos bairro selecionados respectivamente pela Oficina de base. A meta final a ser alcançada pela Oficina de Base é Construir o que denominamos de mapa sócio-cultural-afetivo que sirva de parâmetro para as oficinas da segunda etapa do projeto que irão introduzir os jovens em novos valores e capacitá-los para os princípios básicos do projeto: protagonismo, responsabilização, sociabilidade positiva e exercício consciente da cidadania.

A segunda Etapa do projeto deverá ser de 7 meses em, cada bairro selecionado. A partir do mapa sócio-cultural-afetivo, deverá ter início a segunda etapa do projeto que é a construção coletiva 
e o planejamento, por profissionais especializados, das oficinas de cunho artístico-cultural que serão desenvolvidas no espaço de sociabilidade comum, a Lona Cultural Itinerante. A proposição das oficinas não significa imposição, mas estratégia metodológica para uma aproximação mais efetiva com o publico alvo. As oficinas propostas são quatro: Oficina de Teatro, oficina de Música; oficina de Dança; oficina de Desenho.

\section{A FILOSOFIA}

A Filosofia das oficinas na segunda etapa é articular os 4 principios: protagonismo, responsabilização, sociabilidade positiva e o exercício da cidadania por meio da arte, tendo por base a filosofia de que um projeto social não deve nivelar as atividades somente pelo gosto médio detectado no público alvo. O propósito é oferecer a demanda solicitada, mas também apresentar um leque de opções culturais. (Suassuna: 2013).

A escolha dessas oficinas não é aleatória está sustentada pelo conhecimento teórico e também indiciário baseado na experiência, intuição, pistas, sensibilidade e faro, dos profissionais que entendem a música, a dança, o teatro e o desenho como atividades pedagógicas que permitem a comunicação e possibilitam ler o desejo dos jovens. Para tal, os profissionais que participarão das oficinas serão especialistas no trato com o público alvo com base nos saberes, nas vivências e experiências. Cada jovem é um texto. Desse modo, a ideia da Lona Cultural Itinerante é de um espaço comum onde o jovem possa transitar com liberdade tanto espacialmente como culturalmente nas 4 oficinas, conhecendo e participando num ambiente de diversidade. (Rodrigues: 2005).

\subsection{POLÍTICA CULTURAL: PRODUÇÃO DE INDICADORES}

O propósito das oficinas é atingir os indicadores qualitativos e quantitativos (Jannuzzi: 2006). Os indicadores qualitativos serão alcançados no tempo proposto por este projeto, ou seja, 2 anos, além de permitir o monitoramento e avaliação das metas em curto prazo. Já que a perenidade, ou seja, as metas em médio prazo poderão ser medidas e avaliadas pelos indicadores quantitativos, após o projeto, ao longo de 5 anos.

Os Indicadores qualitativos são: Interesse e participação nas oficinas; Responsabilização; Percepção de valores solidários; Identificação das potencialidades; Percepção da sujeição criminal. Os Indicadores quantitativos são: diminuição do envolvimento dos jovens em atos infracionais; Retorno à escola; Aumento do rendimento escolar; Exercício consciente da cidadania (mensurados pela participação dos jovens em conselhos, movimentos populares, e culturais, exercício de voto consciente etc.). 
A Oficina de teatro será desenvolvida por teatrólogo, auxiliares e o produtor cultural que trabalhará nas 4 oficinas e será responsável por toda logística de infraestrutura e funcionamento da Lona durante o período de duração do projeto, assim como pela captação e contratação dos artistas específicos para cada uma das quatro oficinas, garantindo não só a expertise em relação ao público alvo como também a qualidade do desempenho do artista e cumprimento de prazos. A Atividade desenvolvida será decidida depois da oficina de base. A Meta da oficina 1 é desenvolver atividade que permita introduzir os jovens nos princípios básicos do projeto articulados aos indicadores qualitativos e quantitativos. O prazo de atuação é 7 meses 3 vezes por semana. Produtos: Instrumento de avaliação: 1) Relatórios parciais por meio da observação participante e indiciária; 2) Questionários e estatísticas oficiais; 3) Grupo de enfoque. 4) Mesa de discussão ampliada. Profissionais: sociólogo e psicólogo. A Coordenação geral será responsável pela orientação metodológica geral garantindo a articulação com os quatro princípios básicos que orientam o projeto, bem como auxiliando na produção dos instrumentos de avaliação em cada oficina.

Oficina de música será desenvolvida por musicista, auxiliares e estudantes de artes plásticas. A Atividade desenvolvida será decidida depois da oficina de base. A Meta da oficina 2 é desenvolver atividade que permita introduzir os jovens nos princípios básicos do projeto articulados aos indicadores qualitativos e quantitativos. Período de 7 meses 3 vezes por semana. Produtos: Instrumentos de avaliação: 1) Relatórios parciais por meio da observação participante e indiciária; 2) Questionários e estatísticas oficiais; 3) Grupo de enfoque; 4)Mesas de discussão ampliada. Profissionais: sociólogo, e psicólogo. A coordenação geral será responsável pela orientação metodológica geral garantindo a articulação com os quatro princípios básicos que orientam o projeto, bem como auxiliando na produção dos instrumentos de avaliação em cada oficina.

Oficina de dança será desenvolvida por um coreógrafo e dançarino, auxiliares estudantes de artes plásticas. Atividade será decidida depois da oficina de base. A Meta da oficina 3: Desenvolver atividade que permita introduzir os jovens nos princípios básicos do projeto articulados aos indicadores qualitativos e quantitativos. O prazo de atuação é 7 meses 3 vezes por semana. Produtos: Instrumentos de avaliação: 1) Relatórios parciais por meio da observação participante e indiciária; 2) Questionários e estatísticas oficiais; 3) Grupo de enfoque; 4) Mesas de discussão ampliada; Profissionais: sociólogo e psicólogo. A coordenação geral será responsável pela orientação metodológica geral garantindo a articulação com os quatro princípios básicos que orientam o projeto, bem como auxiliando na produção dos instrumentos de avaliação em cada oficina.

Oficina de desenho será desenvolvida por artista plástico, auxiliares estudantes de artes plásticas. A Atividade desenvolvida será decidida depois da oficina de base. A Meta da oficina 4 será 
desenvolver atividade que permita introduzir os jovens nos princípios básicos do projeto articulados aos indicadores qualitativos e quantitativos. O prazo de atuação é 7 meses 3 vezes por semana. Produtos: Instrumentos de avaliação: 1) Relatórios parciais por meio da observação participante e indiciária; 2) Questionários e estatísticas oficiais; 3) Grupo de enfoque; 4)Mesas de discussão ampliada. Profissionais: sociólogo e psicólogo. A coordenação geral será responsável pela orientação metodológica geral garantindo a articulação com os quatro princípios básicos que orientam o projeto, bem como auxiliando na produção dos instrumentos de avaliação em cada oficina.

\subsection{PROTAGONISMO JUVENIL}

A missão do projeto é oferecer condições para que o protagonismo juvenil realmente aconteça. Não acreditamos no paternalismo e tampouco no assistencialismo. Assim, os indicadores qualitativos deste projeto, não serão nivelados somente pelas demandas solicitadas, mas pelo oferecimento ampliado do universo artístico que incluí a circularidade entre os gostos e as culturas popular e erudita. Não cederemos a demanda sem reflexão crítica. Educar é estabelecer limites, dar forma ao sujeito num exercício conjunto de baixo para cima, entretanto, sem democratismo e paternalismo.

Partimos da perspectiva pedagógica essencialista ou estética, em que as artes são concebidas enquanto linguagens, como sistemas semióticos de representação especificamente humanos. E nesse particular, permite lidar com sistemas complexos, com signos, leituras e compreensão da realidade que, se bem conduzido, pode levar o jovem a se apropriar da linguagem e ampliar sua comunicação.

\footnotetext{
"O objetivo do ensino das artes, para a concepção pedagógica essencialista, não é a formação de artistas, mas o domínio, a fluência e a compreensão estética dessas complexas formas humanas de expressão que movimentam processos afetivos, cognitivos e psicomotores"(JAPIASSU, Ricardo. Metodologia do Ensino de Teatro. Campinas, SP: Papirus, 2001).
}

É nesse encontro que cada jovem poderá rever suas visões de mundo, reencontrar suas expectativas, reafirmar sua identidade e enxergar suas potencialidades. Trata-se de uma ação libertadora para qualquer ser humano que busca, até sem saber, a sua própria expressão. (Reverbel: 1997). Enfatizamos que a prerrogativa fundamental do projeto Lona Cultural Itinerante se assenta no fortalecimento da educação para a paz e a necessidade de uma aproximação mais efetiva e afetiva dos jovens e adolescentes em busca de um processo de sensibilização e conscientização desse sujeito de direitos quanto à sua real importância na sociedade e no futuro do país, por meio do exercício consciente da cidadania. 
1

LATIN AMERICAN JOURNAL OF DEVELOPMENT

Acreditamos que o fortalecimento dos valores que regem a convivência - a solidariedade, a liberdade, o amor, o respeito pela vida (própria e do outro), as diferenças - deve ser impulsionado por meio de projetos e processos pedagógicos que se aproximem desses jovens em momentos essenciais de sua vida cotidiana nos bairros em que vivem. É preciso criar espaços em que seja favorecida a convivência firmada em laços de solidariedade, responsabilização e integração do sujeito para o sucesso do protagonismo juvenil (Kehl: 2008).

A terceira etapa do projeto será o acompanhamento e avaliação, com Duração: 2 meses. A Atividade de acompanhamento se dará com base em avaliações organizadas de forma a contemplar a objetividade e a interatividade da proposta de trabalho. Nesse sentido, iremos consolidar os indicadores quantitativos e qualitativos combinados a partir dos dados obtidos nas oficinas da segunda etapa pelos seguintes instrumentos: Instrumentos de avaliação: 1) Relatórios parciais em cada etapa por meio de observação participante e indiciária. (Esse instrumento oferecerá dados tanto para a correção dos rumos do projeto como para alimentar os indicadores qualitativos; 2) Questionários e estatísticas oficiais. (Esse instrumento oferecerá dados para a construção de indicadores quantitativos; 3) Grupo de enfoque. (Esse instrumento oferecerá dados para os indicadores qualitativos e quantitativos; 4) Mesas de discussão ampliada. Esse instrumento oferecerá dados para os indicadores qualitativos. Profissionais: sociólogo, psicólogo, pedagogo e assistente social.

\subsection{PRODUTOS: INSTRUMENTOS DE AVALIAÇÃO E MONITORAMENTO}

O Produto final do projeto Lona Cultural Itinerante será gerar instrumentos de monitoramento e avaliação dos resultados obtidos; produção de um livro cotendo o relato e análise da experiência; subsídios para um Curso de pós-graduação na metodologia em Formação em Cidadania Cultural (FCC) para capacitar educadores sociais e profissionais que atuam em projetos de intervenção social de prevenção à criminalidade juvenil.

O resultado esperado é atingir em 2 anos avaliação positiva dos indicadores qualitativos na população alvo que participou do projeto nos bairros dos dois municípios em Serra e Vitória. Ou seja, interesse e participação nas oficinas; responsabilização; percepção de valores solidários; identificação das potencialidades; percepção do processo de sujeição criminal. O impacto em médio prazo, ou seja, 5 anos, é obter avaliação positiva em relação aos indicadores quantitativos na população alvo que participou do projeto: Diminuição do envolvimento dos jovens em atos infracionais contribuindo para a diminuição do índice de homicídio juvenil nas áreas de atuação do projeto; retorno à escola; aumento do rendimento escolar; exercício consciente da cidadania e protagonismo. 


\section{REFERENCIAS}

Berlinck, Manoel Tosta (1998). Alexandre e seus irmãos: Psicanálise de Pixotes? In Psicanálise da clínica cotidiana. São Paulo: Escuta.

Jannuzzi, Paulo de Martinho (2006). Indicadores Sociais no Brasil. Conceitos, Fontes de dados e Aplicações. Campinas, SP: editor Alínea.

Japiassu, Ricardo (2001). Metodologia do Ensino de Teatro. Campinas, SP: Papirus.

Kehl, Maria Rita (2008). A fratria órfã: conversas sobre juventude. São Paulo: Olho d’Água.

Misse, Michel (2010). Crime, sujeito e sujeição criminal: aspectos de uma contribuição analítica sobre a categoria "bandido", Lua Nova, São Paulo, 79: 15-38.

Relatório da (OMS) Organização Mundial da Saúde, Genebra: 2014.

Reverbel, Olga (1997). Um caminho do Teatro na escola. São Paulo: Scipione.

Rodrigues, Marcia B.F. (2005) Razão e Sensibilidade: reflexões em torno do paradigma indiciário. Revista Dimensões no 17 . Vitória: UFES, CCHN.

Rodrigues, Márcia B.F. (2009). Metodologia e Pesquisa em Projetos de Intervenção Social: A experiência capixaba no município da Serra, publicado na edição número 6 da Revista Sinais, ISSN: 1981.3988. WWW.nei.ufes.br.

Rodrigues, M.B. F e Dadalto, M.C. (2014) Migração e violência. O baiano na construção da sujeição criminal ma RMGV do ES. In Dilema Revista de Estudos de Conflitos e Controle Social, vol.7 $\mathrm{n}^{\mathrm{o}} 1$, Jan.Fev.Mar. 2014).

Suassuna, Ariano (2013). Palestra conferida no Teatro Guaira, Curitiba.

Waiselfisz, Julio Jacobo (2014). Mapa da violência 2014. Os jovens no Brasil. Flacso: Rio de Janeiro. 